\title{
Amor de don Perlimplín con Belisa en su jardín: una obra teatral satírica
}

\author{
Susana FERRADA \\ Universitat Autònoma de Barcelona \\ susana.ferrada@hotmail.es
}

\section{RESUMEN}

El componente satírico es una constante en el teatro de Federico García Lorca, en el que coexisten, en mayor o menor medida, dependiendo de la obra en cuestión, lo cómico y lo serio, ambas vertientes intrínsecas a la sátira. Dicha combinación, así como el innegable aspecto crítico, inherente a la obra lorquiana, identifican a este autor con la figura del satírico. García Lorca lleva a cabo su crítica sirviéndose del humor, que oscila entre lo puramente jocoso y el humor negro, y se manifiesta mediante el empleo de técnicas tradicionales de la sátira, con idéntico propósito al del satírico: degradar a su objeto de ataque suscitando sonrisa o repulsa. Este artículo analiza en clave de sátira Amor de don Perlimplín con Belisa en su jardín, identificando el objeto de ataque de la sátira lorquiana en esta obra y las técnicas satíricas empleadas por su autor.

Palabras clave: Lorca, sátira, objeto de ataque, humor.

\section{ABSTRACT}

The satirical component is a constant in the theatre of Federico García Lorca, in which coexist, to a greater or lesser extent, depending on the work involved, the comic and serious, both aspects inherent to satire. This combination, as well as the undeniable critical aspect inherent in Lorca's work, identifies this author with the figure of satiric. García Lorca performs his critical making use of humor, which ranges from the purely humorous to black humor, and is manifested by employing traditional techniques of satire, with the same purpose as the satiric: to degrade to the object of attack provoking smile or revulsion. This article discusses about Love of don Perlimplín and Belisa in his garden, identifying the object of attack of Lorca's satire in this work and the satirical techniques used by its author. Key words: Lorca, satire, object of attack, humor. 
Se ha escrito mucho ya sobre Federico García Lorca y su obra. Hasta ahora, la tendencia general ha sido la de basar el estudio, fuera cual fuera el objetivo del mismo, en el aspecto trágico, obviamente presente en la obra de Lorca. Sin embargo, es constante también en su creación literaria el humor, lo cómico, lo jocoso... que, simultáneo a la tragedia que acontece, caracteriza el particular estilo del discurso lorquiano, aspecto, no obstante, del que pocos investigadores han partido para analizar la obra de Lorca. Estudios como The comic spirit of Federico García Lorca de Virginia Higginbotham o The trickster-function in the theatre of Federico García Lorca de Sarah Wright corroboran la relevancia del humor en la obra lorquiana ${ }^{1}$. Más concretamente, sólo el artículo de Héctor Urzáiz Tortajada, "Sátira, farsa y parodia en el teatro juvenil de Federico García Lorca"², vincula a Lorca con la sátira. Cualquier otra referencia a la sátira en los estudios lorquianos no pasa de ser un simple apunte. Nadie ha identificado a Federico García Lorca con la figura del satírico ni ha analizado su teatro en clave de sátira.

La siguiente cita de Hodgart, que sintetiza las características del teatro de Lorca, ratifica dicha propuesta:

Así pues, una obra teatral satírica puede arrastrar a su auditorio a un mundo ensoñado de apariencias, pero los comentarios de su autor deben extenderse al mundo real externo del teatro, a los problemas políticos y morales con que ha de enfrentarse dicho auditorio cuando se reincorpore a la vida ordinaria. De ahí que en la sátira el asunto y la postura que ante él adopta el autor sean de esencial importancia. El satírico se compromete con los problemas del mundo y éste espera que sus lectores hagan lo mismo. Él así lo hace aunque sea consciente de que corre un doble riesgo: el de ser impopular en su propio tiempo y el de ser olvidado por las generaciones futuras, para las cuales los acontecimientos cotidianos de su tiempo tal vez no tengan más que un interés meramente erudito. ${ }^{3}$

Otros teóricos de la sátira, como Gilbert Highet ${ }^{4}$ y Rosario Cortés ${ }^{5}$, coinciden con Hodgart cuando, para definir el término "sátira", hacen hincapié en la actitud crítica del satírico, así como en la capacidad de la sátira para manifestarse en cualquier tipo de expresión literaria.

El propio Hodgart advierte de la dificultad existente al tratar de diferenciar la sátira de los demás géneros, pues, más que un género literario en sí, la sátira es una

1 V. Higginbotham (1976); S. Wright (2000). En su estudio, Higginbotham, comenta parcialmente El público y no hace mención a Comedia sin título, ambas editadas por primera vez en 1978, dos años después de su ensayo. Convendría, por tanto, actualizar este estudio que tampoco incluye el teatro de juventud, inédito hasta 1994.

${ }^{2}$ H. Urzáiz Tortajada (1996).

${ }^{3}$ M. Hodgart (1969), p. 30.

${ }^{4}$ G. Highet (1962), pp. 3-23.

${ }^{5}$ R. Cortés Tovar (1986), p. 77. 
forma de expresarse, consistente en "el empleo al hablar o al escribir del sarcasmo, la ironía, el ridículo, etc., para denunciar, exponer o ridiculizar, el vicio, la tontería, las injusticias o los males de toda especie" ${ }^{\text {, }}$, que puede manifestarse en cualquier género literario, incluida la tragedia. En su clásico estudio sobre literatura comparada, Claudio Guillén advertía de la necesidad de sumar a los conceptos básicos de cauces de representación, géneros y formas, el término modalidades literarias, "tan antiguas y perdurables muchas veces como los géneros, pero cuyo carácter es adjetivo, parcial y no a propósito para abarcar la estructura total de una obra", modalidades entre las que incluía la ironía, lo grotesco, la alegoría, la parodia o la sátira ${ }^{7}$. Por su parte, Rosario Cortés determina que el término sátira denomina "un tono o intencionalidad crítica, que tiñe una obra o una de sus partes y que puede aparecer lo mismo en un poema que en una novela o un drama"8. La gran cantidad de temas objeto de su crítica y la variedad de formas que puede llegar a asumir la sátira dificultan su identificación respecto de los géneros literarios convencionales. Cualquier crítico literario especializado alerta sobre este problema al tratar de acotar los límites del género de la sátira y advierte de la dificultad de dar con una definición que se adecue a obras tan diferentes formalmente.

Resulta especialmente oportuno en este caso, siendo Shakespeare referencia habitual en la obra de Lorca y dada la intensidad de las tragedias de ambos, que los teóricos de la sátira destaquen la presencia de sátira en las tragedias del dramaturgo inglés ${ }^{9}$. Obviamente, Lorca tampoco concibió sus obras íntegramente como sátiras. Profundamente comprometido, reivindicó la verdad en sus obras que son trágicas como la vida misma. Sin embargo, todas ellas son sustancialmente críticas y en todas ellas Lorca recurre a técnicas propias de la sátira como la tipificación, la caricatura, la destrucción del símbolo, la parodia, el desenmascaramiento y la ironía con idéntico propósito al del satírico: reducir hasta la mayor degradación a su objeto de ataque. Por tanto, la producción teatral de Lorca, en mayor o menor grado dependiendo de la obra en cuestión, reúne los dos rasgos esenciales que caracterizan la sátira: el humor, que se manifiesta mediante las mencionadas técnicas reductivas, suscitando sonrisa o repulsa, y un objeto de ataque ${ }^{10}$.

El leitmotiv del teatro de Federico García Lorca resulta ser su objeto de ataque: la realidad, entendida como resultado de la instauración de la norma, siempre opresora, pues integra en la sociedad a quien la acata, pero obliga a cada individuo a

\footnotetext{
${ }^{6}$ M. Hodgart (1969), p. 7.

${ }^{7}$ C. Guillén (1985), p. 165.

${ }^{8}$ R. Cortés (1986), p. 77.

${ }^{9}$ M. Hodgart (1969), p. 12.

${ }^{10}$ Según Northrop Frye, "Two things, then, are essential to the satire; one is wit humor founded in fantasy or a sense of the grotesque or absurd, the other is an object of attack. Attack without humor, or pure denunciation, forms one of the boundaries of satire". N. Frye (1973), p. 224.
} 
renegar de aquello que lo distingue. García Lorca denunció "la pobreza de la realidad" 11 que, al no tolerar la diferencia, uniformiza las conductas y fomenta la hipocresía. Su producción teatral constata su empeño por desterrar de los escenarios la representación mimética de esa realidad adulterada por la apariencia, penetrando tras lo aparente, evidenciando la mentira que impera en la realidad oficial, distorsiona la verdad y convierte la vida en una absurda farsa. El humor de Lorca, réplica a la farsa de la existencia, oscila entre el esbozo de la sonrisa irónica y la carcajada grotesca. El suyo es un ataque abierto e incisivo a los convencionalismos y prejuicios que convierten la vida en un absurdo no permitiendo el disfrute de ese efímero momento.

A pesar de poder constatar la presencia de sátira en el conjunto del teatro de Lorca, es imposible, por falta de espacio, establecer paralelismos entre otras piezas lorquianas y la que aquí nos ocupa. Este artículo es un avance de mi tesis doctoral, en la que se aborda el análisis, en clave de sátira, de la mayor parte del teatro lorquiano de madurez, haciendo referencia incluso al teatro de juventud, en el que Lorca mostraba ya la misma intencionalidad satírica que en su obra posterior.

El presente artículo se centra en el estudio de Amor de don Perlimplín con Belisa en su jardín con el propósito de identificar el objeto de ataque y las técnicas satíricas empleadas por Lorca en esta obra e incidir en esta dimensión que consideramos transversal en su producción. Lo inicialmente burlesco devendrá grotesco en contraste con el carácter serio o elevado del objetivo de dichas alusiones. Así lo advertía Lorca el mismo día del estreno, el 5 de abril de 1933, en declaraciones a El Sol: "Lo que me ha interesado en don Perlimplín es subrayar el contraste entre lo lírico y lo grotesco y aún mezclarlos en todo momento" "12. Esa hibridación entre el lirismo y lo grotesco sobre la que Lorca advertía, ambas vertientes intrínsecas a la sátira, caracteriza la tragedia de vanguardia ${ }^{13}$, que se sirve del carácter transgresor de la farsa para arremeter contra la falsa verosimilitud del teatro burgués y renovar o, lo que es lo mismo, "airear y ennoblecer el teatro de su tiempo"14. En un horizonte de expectativas marcado por las propuestas valleinclanianas, Lorca, a fin de evitar el rechazo del público, opta por un camino menos radical, y por ello aparentemente menos efectivo, que sabrá llevar hasta límites insospechados: la aleluya ${ }^{15}$.

\footnotetext{
${ }^{11}$ F. García Lorca (1997a), p. 375.

12 F. García Lorca (1997), Vol. III, p. 409.

${ }^{13}$ M. Iglesias Santos (1999), pp. 163-174.

14 J. Huerta Calvo (1992), p. 292.

15 “La 'aleluya' a la que alude el subtítulo era -más aún que las marionetas y la farsa- una superficie, un solo plano que la convertía acaso en el más limitado y convencional de los espectáculos. En sus gestos y sus viñetas no tenían cabida más que los grandes gestos, los epítomes de la acción, lo más explícito y abarcador del discurso", L. Fernández Cifuentes (1986), p. 119.
} 
En el primer cuadro, Lorca retrata a los personajes empleando la tipificación, técnica reductiva a la que recurre frecuentemente la sátira y que, además, es "recurso esencial de la comedia escénica y del humor irónico", puesto que "verse reducido a un tipo es una circunstancia menos terrible que verse reducido a un animal, a un loco o a una máquina, pero es con todo bastante desagradable. Implica, aunque menos rigurosamente, que la figura-tipo nunca puede salirse del papel que le ha sido impuesto, ni actuar con libertad"16.

En este sentido, la figura-tipo de don Perlimplín se mimetiza con su entorno. Viste de verde, el mismo color de las paredes de su casa. Arraigado a ella hasta el punto de fundirse con su interior, Perlimplín es la imagen de la rutina y del tedio. $\mathrm{Su}$ traje y su peluca ${ }^{17}$, pasados de moda, denotan que es un viejo anticuado, cualidades a las que se suma una pasividad que justifica de modo libresco: "Yo con mis libros tengo bastante" $" 18$, dice a Marcolfa. El libro, que en la obra de Lorca simboliza fijeza, paralización, es otra evidencia de la falta de acción en la vida de Perlimplín ${ }^{19}$. Tanto la paralización como la mimética son un recurso defensivo de algunas especies animales que don Perlimplín parece emplear para pasar

16 M. Hodgart (1969), pp. 120-121. Mis argumentaciones se basan fundamentalmente en esta obra de Hodgart porque este teórico enumera todas las técnicas satíricas describiendo su funcionamiento y su propósito. Dado que mi objetivo es demostrar que Lorca fue un satírico, resulta fundamental probar que empleó técnicas satíricas, identificando cada una de ellas en la obra que aquí se analiza.

${ }^{17}$ En su edición de Amor de don Perlimplín con Belisa en su jardín, Margarita Ucelay advierte que el impacto visual del decorado en verde y negro, así como el verde de la casaca de Perlimplín, responden al contraste violento del negro mate que enmarcaba las viñetas de las aleluyas y al de las marcadas líneas del grabado xilográfico sobre el color chillón del papel en el que éstas se imprimían. En cuanto a la ambientación y vestuario dieciochescos, M. Ucelay lo cree deudor del ambiente del s. XVIII que evocaban las aleluyas de don Perlimplín. M. Ucelay también estudia la posibilidad que apunta Francisco García Lorca de que la "aleluya erótica" fuera un libreto de ópera con el que Federico se hubiera desquitado de su truncado proyecto en colaboración con Falla El calesero, más conocida como Lola la comedianta, propósito que explicaría la esencia musical del Perlimplín. Contemplando esa posibilidad, según Ucelay, la recreación dieciochesca sería esencial para conseguir la atmósfera de época correspondiente a las sonatinas de Domenico Scarlatti, escogidas por Federico para amenizar los entreactos de la obra el día de su estreno. M. Ucelay (2005)

${ }^{18}$ F. García Lorca (1997b), p. 243. Todos los fragmentos de Amor de don Perlimplín con Belisa en su jardín citados en adelante serán referenciados teniendo en cuenta la misma edición, por ello anotaré la página correspondiente junto a cada fragmento sin volver a citar dicha edición a pie de página.

19 "En general, en el discurso de García Lorca (incluso en el autobiográfico), los 'libros' no sólo constituyen una referencia marginal y precavida, sino que connotan de diversos modos la fijeza, la paralización [...]. Igualmente los libros se asocian también a lo viejo, lo concluido". L. Fernández Cifuentes (1986), p. 126. 
desapercibido, evitando el riesgo, posible daño o desengaño, que conlleva cualquier acción.

Belisa, de ostentosa exuberancia, es la caracterización de la feminidad y la sensualidad, la antítesis de Perlimplín. Joven, hermosa y vital, será para éste el estímulo determinante que lo despertará de su letargo y lo convertirá en un hombre de acción. En el primer cuadro, se advierte el despertar de Perlimplín cuando su organismo reacciona ante la desbordante sexualidad de Belisa experimentando su primera erección ${ }^{20}$. Esa reacción física, reflejo incontrolado, vergonzoso desde el punto de vista de la moral tradicional y, por ello reprimido, evidencia el tabú que genera lo normativo y denuncia la ignorancia que conlleva. Mediante un ejemplo hiperbólico, consecuencia del error en el que incurre la educación tradicional, que no permite ver más allá de sus convenciones sociales y éticas, Lorca desacredita el dictamen de la norma. Don Perlimplín, a quien de nada sirve el saber que le han proporcionado sus libros, es víctima de una moral tradicional que su falta de experiencia no le ha permitido cuestionar, desconocimiento que resulta chocante en quien ya ha cumplido los cincuenta ("¿Y qué es esto que me pasa?... ¿Qué es esto?", 246) y que lo muestra como un ser patético e incapaz de atisbar el ridículo al que se está exponiendo. Lorca denuncia la opresora moral tradicional, empeñada en neutralizar lo irracional en el hombre, su instinto, que lo rebaja a la condición de animal y que por tanto resulta deshonroso y humillante. La moral tradicional se evidencia absurda cuando, incapaz de sofocar dichas reacciones, fomenta y tolera la hipocresía. Así se advierte en las palabras de Marcolfa, portavoz de la norma: "El matrimonio tiene grandes encantos, mi señor. No es lo que se ve por fuera. Está lleno de cosas ocultas. Cosas que no está bien que sean dichas por una servidora... Ya se ve... [...] Me he puesto colorada" (243). Nótese cómo, hasta ahora y en adelante, durante toda la obra, la intención de Lorca es transgredir y degradar las convenciones socio-culturales, propósito reductivo que caracteriza la sátira.

Es cómico el diálogo inicial entre Perlimplín y Marcolfa. Ambos utilizan idénticas palabras en sentido inverso. Marcolfa trata de imponerse, mientras Perlimplín le da réplica cuestionando burlonamente su dictamen mediante una especie de cantinela infantil que contradice lo que la norma da por válido siempre que ésta intenta imponerse. Formulando una nueva pregunta a cada intento de Marcolfa por convencerlo de que debe casarse, Perlimplín resta validez a los

20 Emilio Peral Vega interpreta del mismo modo las palabras de Perlimplín al final del primer cuadro: “¿Y qué es esto que me pasa?... ¿Qué es esto?”. E. Peral Vega (2001), pp. 223-244. M. Balboa Echeverría propone la misma interpretación en su artículo "The Inner Space in The Love of Don Perlimplín and Belisa in His Garden", véase L. Fernández Cifuentes (1986), p. 121. 
argumentos de su criada ${ }^{21}$. Ésta persevera en su propósito, a pesar de la patente falta de consistencia de sus razonamientos. La razón por la que Perlimplín debe casarse responde a absurdos convencionalismos y, ante esa evidencia, la norma se impone por la fuerza, "porque sí":

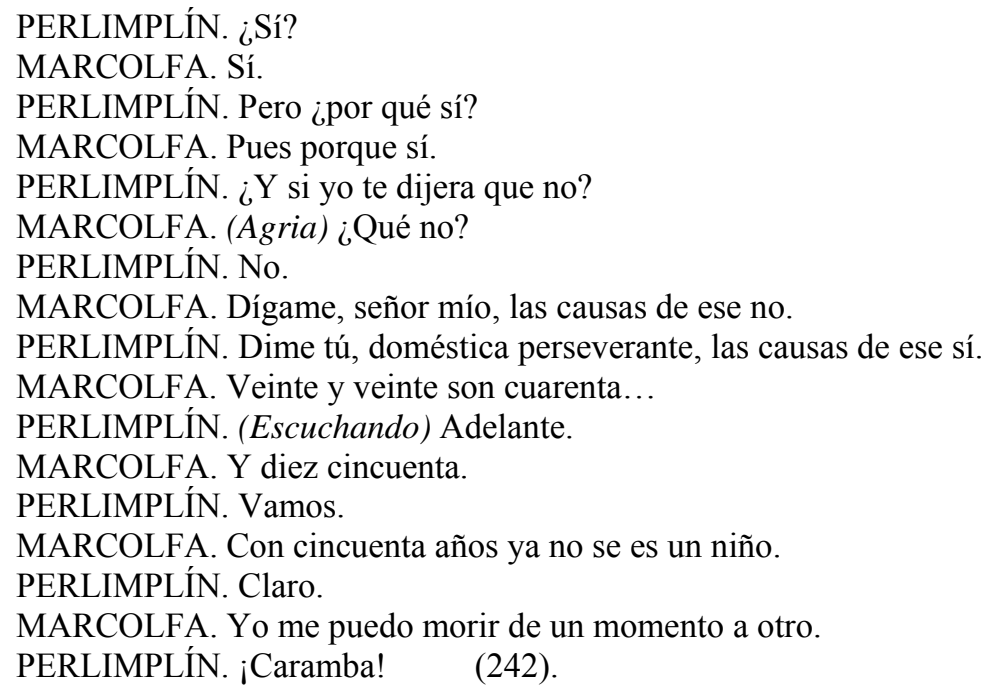

La ironía de Perlimplín devalúa el tono trágico que Marcolfa emplea para persuadirle. Su indiferencia implica una referencia burlesca a la muerte, pues quita relevancia al carácter definitivo y dramático de ésta. Resulta igualmente chistoso el argumento de Perlimplín para desmentir que el matrimonio sea un estado ideal. La imagen inverosímil de una mujer estrangulando a su marido, que sin embargo asusta a Perlimplín, provoca risa. Siendo el matrimonio causa de muerte, el "hasta que la muerte os separe" resulta una sentencia lapidaria, un irónico epitafio: "Perlimplín. (Angustiado.) Pero Marcolfa... ¿por qué sí? Cuando yo era niño una mujer estranguló a su esposo. Era zapatero. No se me olvida. Siempre he pensado no casarme. Yo con mis libros tengo bastante. ¿De qué me va a servir?” (242-243).

Asimismo, Perlimplín se pone en ridículo al confesar su miedo a la mujer, consecuencia de un trauma infantil no superado, impropio de la madurez que debería haber alcanzado a su edad. En este primer cuadro, el retrato que Lorca hace de Perlimplín se corresponde con el de una figura-tipo: viejo inocentón, inmaduro, ignorante, miedoso y sumiso es incapaz de imponerse al dictamen de la norma y actuar con libertad. Así se manifiesta en su primera conversación con Belisa.

${ }^{21}$ Francisco García Lorca estudia la musicalidad de este diálogo inicial entre Perlimplín y Marcolfa. F. García Lorca (1981), pp. 315-317. Por su parte, Emilio Peral Vega también advierte el tono infantil que caracteriza a este diálogo. E. Peral Vega (2001), p. 224. 
Perlimplín, asustado y sin determinación, no es quien realmente habla, es Marcolfa quien lo hace por boca de su amo. Perlimplín es un pelele manipulado por Marcolfa y prueba de ello es que, cuando éste se dirige a Belisa para proponerle matrimonio, utiliza idénticas palabras a las empleadas por su criada para convencerlo de que debía casarse, hasta el punto de reproducir el cómico diálogo que abría el cuadro. En esta ocasión, Marcolfa se reafirma por boca de Perlimplín, mientras Belisa cuestiona su criterio:

\title{
BELISA. ¿Sí?
}

PERLIMPLÍN. Sí.

BELISA. Pero ¿por qué sí?

PERLIMPLÍN. Pues porque sí.

BELISA. ¿Y si yo le dijese que no?

PERLIMPLÍN. Lo sentiría... porque... hemos decidido que me quiero casar (244).

La misma cantinela de tono infantil y burlón vuelve a repetirse en el cuadro segundo, nuevamente para cuestionar lo supuesto por la voz del canon:

\author{
PERLIMPLÍN. Belisa... ¡Yo te amo! \\ BELISA. ¡Oh caballerito!... es ésa tu obligación. \\ PERLIMPLÍN. ¿Sí? \\ BELISA. Sí \\ PERLIMPLÍN. Pero ¿por qué sí? \\ BELISA. (Mimosa.) Pues porque sí (248-249).
}

De esta manera, don Perlimplín refuerza su condición tipificada al adivinarse en su persona el estereotipo del viejo cornudo, monigote vapuleado por esa moral tradicional que, a pesar del evidente fracaso que va a suponerle, le exige seguir el programa, cumplir con el rito del matrimonio.

La Madre, por su parte, es la personificación de la autoridad familiar, que Lorca caricaturiza como nueva personificación de la norma, vigente a pesar de ser anticuada, válido referente moral, a pesar de fomentar la hipocresía, ser déspota y opresora, incongruencias que Lorca siempre denunció. Su aspecto arcaico, lleva "una gran peluca dieciochesca" (244), es el reflejo de la vieja tradición que legitima su potestad. Un aspecto ostentoso que ridiculiza la imagen solemne de las autoridades, recurso intimidatorio que les garantiza respeto. Los pájaros, cintas y abalorios que adornan su imponente peluca bien podrían ser una referencia burlesca a las condecoraciones, símbolos de poder que distinguen a la autoridad. Lorca emplea aquí una técnica fundamental en la sátira: la destrucción del símbolo, pues, como "el satírico que desea demostrar que un emblema está siendo usado con fines injustos o manejado por tiranos o demagogos, no pretende comprender sus connotaciones simbólicas, sino que presenta la cosa en sí misma con el mayor 
realismo posible: la bandera es exactamente una pieza de tela",22. Del mismo modo, Lorca reduce los símbolos del poder a simples abalorios y los desprovee de su valor honorífico distintivo. La solemnidad de la que hace gala la Madre es pura fachada. La imponente y recargada peluca denota falsedad en la personalidad que adorna. Además, la Madre emplea el lenguaje de la autoridad que Lorca parodia. En su discurso es evidente la demagogia, intrínseca a este tipo de retórica y es patente y reiterada la falsedad en cada uno de los halagos con que engatusa a Perlimplín: "Buenísimas tardes, encantador vecinito mío. Siempre dije a mi pobre hija que tiene usted la gracia y modales de aquella gran señora que fue su madre y a la cual no tuve la dicha de conocer" (244). La Madre se burla de Perlimplín descaradamente utilizando la ironía, como cuando le define como "persona moderna y competentísima" (245) queriendo decir lo contrario. Ella misma se delata, sin embargo, a pesar de la evidencia, Perlimplín es incapaz de intuir el engaño:

MADRE. Es una azucena... Ve usted su cara. (Bajando la voz.) Pues si la viese por dentro... ¡Como de azúcar!... Pero... ¡perdón! No he de ponderar estas cosas a una persona tan moderna y competentísima como usted...

PERLIMPLÍN. ¿Sí?

MADRE. Sí... lo he dicho sin ironía (245).

La Madre vuelve a emplear la ironía para mofarse de Perlimplín que, absurdamente, no ha cesado de emplear la primera persona del plural, en lugar de la primera del singular: "No sé cómo expresarle nuestro agradecimiento..." (245). La Madre no oculta su perplejidad y se burla de la insistencia con que don Perlimplín emplea el "nosotros": "¡Oh!... nuestro agradecimiento... qué delicadeza tan extraordinaria. El agradecimiento de su corazón y el de usted mismo... Lo he entendido... lo he entendido... A pesar que hace veinte años que no trato a un hombre" (245).

"Su corazón y usted mismo", lejos de ser un cumplido, hace referencia a la falta de hombría de Perlimplín. La sensibilidad a la que la Madre achaca, burlonamente, el uso del "nosotros" es impropia del estereotipo masculino socialmente aceptado. Irónica y jocosamente, la Madre alude a la falta de hombría de Perlimplín, pues su inexperiencia e inseguridad se advierten en su manera de hablar. El canon no ha cambiado, a pesar de los veinte años que hace que no trata con un hombre $\mathrm{y}$, obviamente, don Perlimplín no se ajusta a ese modelo. El comentario de la Madre se muestra acorde con la tradición que legitima ese modelo, sin embargo, implícita e irónicamente, Lorca denuncia que la norma vigente es un arcaísmo.

García Lorca ha informado al público del propósito que mueve a cada uno de los personajes. Sobre el escenario, ha mostrado conductas e inquietudes habituales con la intención de apelar a la conciencia del espectador que debe ser crítico,

${ }^{22}$ M. Hodgart (1969), p. 123. Con el mismo propósito, Lorca llamó a la bandera "trapo de colores". Véase F. García Lorca (1997c), p. 731. 
reflexionar sobre su comportamiento y cuestionar la validez de la norma que lo rige $^{23}$. El sinsentido de la hipocresía social se reproduce en esta disparatada escena: Marcolfa persuade a Perlimplín de que debe casarse y, oculta tras la cortina, dicta a éste todo lo que debe hacer y decir para concertar su boda con la joven y bella Belisa. La Madre acalla la impulsiva negativa de Belisa, que lógicamente no quiere casarse con un viejo. Pero, secretamente, sin que lo adviertan ni Perlimplín ni Marcolfa, cuya presencia ambas ignoran, pues se oculta tras la cortina, la Madre instruye a Belisa en el ventajoso negocio que supone casarse con un viejo adinerado. Mientras, Perlimplín es incapaz de hacer valer su opinión e imponer su deseo de no casarse, rebelándose así contra la obligación de hacerlo.

Es cómico el tándem que forman Marcolfa y Perlimplín, de una parte, y la Madre y Belisa de otra. Ambos simulan y disimulan. Lo cómico y absurdo de la escena se agudiza al tener en cuenta que Lorca está parodiando el comportamiento del público, "monigotes humanos", que se ríen de ellos mismos, al contemplar su propio drama, mientras creen reírse del patético Perlimplín ${ }^{24}$. Como la suya, toda vida es un aprendizaje condicionado por prejuicios y convencionalismos socioculturales, un recorrido de la cuna a la tumba como el que describían las aleluyas $^{25}$ que "empieza en burla y acaba en trágico".

Ese disparatado y ridículo juego de suplantaciones culmina con la aparición de los Duendes. Su misión de "tapar las faltas ajenas" (250) evidencia la suplantación apariencia-realidad. Los Duendes descubren ante el espectador "secretos que ya sabía" (250), "cosas que no está bien que sean dichas", "cosas ocultas" (243): la hipocresía y el tabú. La constante referencia en su diálogo a ese tapar y destapar, cubrir y descubrir, obliga a reflexionar al público acerca de esa frecuente práctica que se evidencia absurda. Por otra parte, el diálogo de los Duendes "alude también al público como voyeur, indagador de 'faltas ajenas' que 'se va a las cosas turbias para descubrir en ellas secretos turbios que ya sabía' y que 'está impaciente' porque concluya esta pausa ciega" ${ }^{\prime 2}$. El espectador ha sido desenmascarado: su categoría social y la virtud aparente que pueda denotar su aspecto no ocultan ya la

${ }^{23}$ Uno de los bocetos de Amor de don Perlimplín con Belisa en su jardín editado por Margarita Ucelay, el identificado como boceto A, prueba la intención de Lorca de apelar a la conciencia del espectador consiguiendo que éste se identifique con los personajes: "El personaje no se debe dar cuenta de nada pero si el publico, el drama debe estar en el publico pero no en los personajes. [...] Son fórmulas matemáticas frias y el publico lee el problema que llevan dentro como los personajes". M. Ucelay (2005), pp. 39-41.

${ }^{24}$ Me remito a las declaraciones de Federico García Lorca el día previo al estreno de Amor de don Perlimplín con Belisa en su jardín: "Esta 'aleluya erótica' es una obra tremenda que a mí me divierte mucho. Teatro de monigotes humanos, que empieza en burla y acaba en trágico. [...]”. F. García Lorca (1997d), p. 406.

${ }^{25}$ H. Grant (1964), pp. 307-314.

${ }^{26}$ L. Fenández Cifuentes (1986), p. 128. 
corrompida verdad que cubren. Una vez más, Lorca emplea una técnica esencial en la sátira, ya que "el desenmascaramiento es una versión de la reducción, pero va mucho más lejos que las demás. El satírico se niega a consentir que los satirizados se queden con una personalidad propia ni con ningún secreto"27. El inciso de los Duendes responde al propósito didáctico ${ }^{28}$ del teatro de Lorca, quien pretendía educar al público en lo ético del mismo modo que el satírico: haciéndolo consciente y partícipe de la "realidad verdadera" 29 .

La escena de los Duendes nos remite a la técnica satírica de contraste entre apariencia y realidad, utilizada por satíricos como Quevedo y Luis Vélez de Guevara $^{30}$. Dicha técnica requiere de la magia para desenmascarar la farsa y descubrir la verdad. En este caso, los Duendes son el elemento mágico y descorrer la cortina es un gesto alegórico, equivalente a descubrir la farsa, presente en mayor o menor medida, en la vida de cualquier individuo. El público, implícito en el diálogo de los Duendes, es señalado por éstos, que apelan a su sentido común mostrándoles la verdad:

DUENDE $2^{\circ}$. Y qué te parece. Siempre es bonito tapar las faltas ajenas.

DUENDE $1^{\circ}$. Y que luego el público se encargue de destaparlas. (250)

Indirectamente, los Duendes increpan al público que debe reflexionar sobre las consecuencias del constante y absurdo juego de suplantaciones que había empezado en tono de risa en el cuadro anterior pero que, una vez implícito el espectador, se torna más punzante:

DUENDE $1^{\circ}$. [...] no es justo poner ante las miradas del público el infortunio de un hombre bueno.

\footnotetext{
${ }^{27}$ M. Hodgart (1969), p. 128.

${ }^{28}$ En su célebre "Charla sobre teatro" Federico García Lorca afirmó: "el teatro es uno de los más expresivos y útiles instrumentos para la educación de un país" y "el teatro es una escuela de llanto y de risa". Tal como nuestro autor lo concebía, el teatro tiene el deber de educar aprovechando su capacidad para emocionar. Así como se emocionó Federico, siendo todavía un niño, con el teatro de títeres o vibró con representaciones como El alcázar de las perlas de Francisco Villaespesa a cuyo estreno en Granada, tal como documenta Ian Gibson, acudió con su amigo Manuel Ángeles Ortiz, el futuro pintor que habría de triunfar en París. Véase respectivamente, F. García Lorca (1997e), p. 255 e I. Gibson (1998), p. 54.

${ }^{29}$ F. García Lorca (1997f), p. 763.

${ }^{30}$ En El mundo por de dentro de Quevedo, el Desengaño denuncia la hipocresía del mundo empleando una cuerda que muestra la corrompida moral de todo aquel que pasa por debajo. F. de Quevedo (1993), p. 302. Por su parte, Luis Vélez de Guevara muestra la hipocresía de Madrid haciendo que el Diablo Cojuelo levante el techo de los edificios de la capital dejando así la verdad al descubierto. L. Vélez de Guevara (1999), p. 20.
} 
DUENDE $2^{\circ}$. Es verdad, compadrillo: que no es lo mismo decir "yo he visto" que "se dice". (251)

La imagen de Perlimplín "con unos grandes cuernos de ciervo en la cabeza" (251) es la imagen bufa del cornudo e, implícitamente, el retrato de una sociedad cruel que maltrata a "un hombre bueno" (251). Es el tópico satírico del mundo al revés que, en este caso, premia el mal comportamiento en lugar del bueno. La virtud no tiene cabida en una sociedad corrompida. Como es habitual en la sátira, Lorca muestra imágenes entrañables: la de un "patito recién nacido" en el caso de Amor de don Perlimplín (251), la ovejita "blanca tan chiquita que casi no puede andar" de La zapatera prodigiosa ${ }^{31}$ o la maternidad de Comedia sin título ${ }^{32}$, destruidas por la sociedad para denunciar su crueldad y falta de humanidad. Perlimplín, inocente como un chiquillo, pues a pesar de sus cincuenta años desconoce el comportamiento adulto, es una variante del niño que, en ocasiones, emplea el satírico como portavoz o máscara:

En su capacidad como destructor de símbolos, el satírico o bien se inventa un portavoz o bien adopta una persona o máscara. [...] Puede ser éste un niño o un salvaje que no comprenden las normas de la sociedad adulta o civilizada, y que se niegan a admitir los valores simbólicos que dicha sociedad concede a objetos o acciones aparentemente triviales [...]. El niño y el primitivo no están "educados" porque no han aprendido a atribuir importancia simbólica a las cosas en sí; pero, [...], pueden mostrarse sumamente inteligentes y lógicos en el enfrentamiento con las complejidades del mundo, y sin duda alguna más honestos emocionalmente que los mundanos. ${ }^{33}$

Lorca expone al personaje de Perlimplín, honesto y vulnerable, a los peligros de un mundo corrupto para denunciar la falta de humanidad y reconsiderar sus valores. La idílica apariencia de Belisa contrasta con su interior turbio y cruel, pues burla a su marido aprovechando premeditadamente su vulnerabilidad, sin sentir remordimiento. En este caso, es evidente el contraste entre apariencia y realidad: Belisa encierra un interior oscuro y perverso, en contraste con la blancura y pureza que simboliza la azucena con la que su madre la compara: "Es una azucena... Ve usted su cara. (Bajando la voz.) Pues si la viese por dentro... ¡Cómo de azúcar!...” (245). Perlimplín, recordando al desgraciado zapatero estrangulado por su mujer, cuestiona que la cara sea el reflejo del alma y que el matrimonio sea un estado

${ }^{31}$ F. García Lorca (1997g), p. 212.

${ }^{32}$ F. García Lorca (1997h), p. 772.

${ }^{33}$ M. Hodgart (1969), pp. 125-126. El niño se corresponde con la figura del ingenu a la que Frye atribuye las mismas cualidades: "no tiene opiniones dogmáticas propias pero tampoco admite ninguna de las premisas que hacen que los desatinos de la sociedad parezcan lógicos a quienes están acostumbrados a ellos”. N. Frye (1977), p. 306. 
ideal: “¡Como de azúcar!... blanca por dentro. ¿Será capaz de estrangularme?” (246).

La dulce Belisa resulta ser lo contrario a lo ponderado por su madre. Ella misma se desenmascara mostrándose cruel al burlar a don Perlimplín, reducido cómicamente en una escena que, a pesar de su crueldad, provoca risa:

PERLIMPLÍN. ¿Por qué están los balcones abiertos?

BELISA. Porque esta noche ha corrido el aire como nunca.

PERLIMPLÍN. ¿Por qué tienen los balcones cinco escalas que llegan al suelo?

BELISA. Porque así es la costumbre en el país de mi madre.

PERLIMPLÍN. Y ¿de quiénes son aquellos cinco sombreros que veo debajo de los balcones?

BELISA. De los borrachitos que van y vienen, Perlimplinillo, jamor! (252).

Nada ni nadie es lo que parece. La apariencia suplanta a la realidad. Al igual que Quevedo en El mundo por de dentro, Lorca denuncia una evidencia: el antagonismo entre "un fuera ilusorio y mentiroso [...] y un dentro oculto más o menos vergonzoso" 34 . Lorca denuncia la falsedad de lo aparente que sitúa en un plano superficial y reivindica la verdad oculta, por ello relegada siempre a un plano interno o subterráneo. Así lo confiesa el propio Lorca, en clara alusión quevedesca, por boca del Zapatero en La zapatera prodigiosa cuando hace decir a su personaje, disfrazado de titiritero, "enseño el mundo por dentro" 35 , antagonismo que derivará en El público en la oposición teatro al aire libre y teatro bajo la arena.

En Amor de don Perlimplín, Lorca se atreve a abordar abiertamente el tabú del adulterio. La cortina de tonos grises que corren los Duendes es una referencia burlona al tupido velo que corremos para callar, omitir o dar al olvido asuntos a los que no es conveniente hacer mención. El adulterio, considerado una inmoralidad según el dogma social y religioso es, sin embargo, una costumbre extendida que se mantiene en secreto. La imagen bufa del cornudo es utilizada por Lorca para señalar al adúltero, desmitificar la institución del matrimonio y poner de manifiesto la hipocresía social que incumple la norma que aparentemente profesa. Lorca da al traste con el dogma sobre el que se cimienta la sociedad, a la que, como todo satírico, hace desmoronarse de un plumazo.

La tradición fomenta la hipocresía porque pretende uniformizar las conductas al imponer un comportamiento estereotipado, condenando al escarnio a quien transgrede ese canon. Ese modelo, que implica en sí mismo una tipificación, excluye lo diferente $\mathrm{y}$, en una manifestación de desprecio, tiende a tipificar cualquier comportamiento que no se le ajuste, de ahí por ejemplo el arquetipo del viejo cornudo. Don Perlimplín, una vez esclarecida la verdad y ensanchadas las

\footnotetext{
${ }^{34}$ C. Vaíllo Torres (1977), p. 74.

${ }^{35}$ F. García Lorca (1997g), p. 224.
} 
miras de su conocimiento, declarándose "fuera del mundo y de la moral ridícula de las gentes", (257) denuncia la moral tradicional y propone revelarse contra las limitaciones que ésta impone a los hombres.

El tono jocoso del título Amor de don Perlimplín con Belisa en su jardín, que hacía prever, inicialmente, un desenlace igualmente jocoso, se recrudece en la segunda mitad de la obra. La sorna y la ironía que Perlimplín emplea al hablar con Belisa en el cuadro anterior resultan cínicas: "Yo me doy cuenta de las cosas. Y aunque me hieren profundamente comprendo que vives un drama"; "Yo sé que tú me eres fiel y lo sigues siendo"; "Por eso quiero ayudarte como debe hacer todo buen marido cuando su esposa es un dechado de virtud..." (255-256); "Como soy un viejo quiero sacrificarme por ti. Esto que yo hago no lo hizo nadie jamás" (257).

La transición de lo farsesco a lo trágico señalada por el propio Lorca puede entenderse así mismo como una transición paralela de lo cómico o jocoso y bufo al humor negro. Es decir, la burla de don Perlimplín sobrepasa el tono ligero que caracteriza la farsa, siendo lícito emplear el término humor negro que contribuye a generar esa sensación de desconcierto en el espectador como un efecto más puesto al servicio del desenlace trágico. Lo cómico o jocoso del último cuadro se limita a la canción bufa que entona don Perlimplín: “¡Don Perlimplín no tiene honor!/ ¡No tiene honor!" (259) y a la intervención de Belisa: "Don Perlimplín /marido ruin, /como le mates /te mato a ti" (262). El verso "iSe mueren de amor los ramos!" (260) que Perlimplín intercala en la canción recitada por Belisa, y que repite insistentemente tras la intervención del coro, supone una intrusión inquietante de lo imprevisto que amenaza lo previsible, lo preestablecido, sesgando las expectativas de Belisa. La intervención de Perlimplín tiene connotaciones burlonas al tiempo que advierte, cínicamente, de la tragedia que está a punto de acontecer. Más tarde, haciéndose eco de la premonición implícita en "¡Se mueren de amor los ramos!", Perlimplín dirá: “... pero me ha matado... con este ramo ardiente de piedras preciosas" (263), consumando así su burla.

Perlimplín rechaza el patético y ridículo arquetipo al que ha quedado reducido rebelándose con una reacción sin precedentes. Fuera de todo lo previsible, al margen de lo contemplado en la tradición literaria, el final de Amor de don Perlimplín con Belisa en su jardín es una versión inédita del clásico argumento del burlador burlado ${ }^{36}$. La nueva perspectiva de Perlimplín, que ahora es capaz de

\footnotetext{
${ }^{36}$ Sobre las irregularidades de Amor de don Perlimplín... con respecto al clásico tema del viejo cornudo, Fernández Cifuentes apunta: "El marido puede entonces resultar ignorante, consentido o vengador. Perlimplín, que participa conscientemente en el juego, no sólo adopta las tres alternativas; las superpone y las combina con una lógica nueva y desconcertante que desbarata el reglamento". L. Fernández Cifuentes (1986), p. 128. Asimismo, en su artículo "El viejo y la niña: tradición y modernidad en el teatro de Lorca", Fernández Cifuentes recoge las diferentes soluciones que la tradición literaria ha dado al
} 
pensar "todo lo que no había pensado antes" (258) le proporciona el ingenio necesario para burlar a su esposa, llevando así a cabo su venganza. La inesperada reacción de Perlimplín altera el orden regular, preservado por los preceptos de la norma, al quebrantar la secuencia ritual preestablecida. La Madre, portavoz del canon, segura de lo inamovible de su dictamen, vaticinaba en el cuadro primero: "Don Perlimplín es un encantador marido/ Don Perlimplín tiene muchas tierras. En las tierras hay muchos gansos y ovejas. Las ovejas se llevan al mercado. En el mercado dan dineros por ellas. Los dineros dan la hermosura... Y la hermosura es codiciada por los demás hombres" (244).

El suicidio de don Perlimplín, que desbarata ese guión, conlleva una "inversión de valores" ${ }^{, 37}$ : lo normativo o preestablecido es marginado en favor de la imaginación, siempre transgresora, cuyo triunfo proclama Perlimplín: "Ése es mi triunfo. [...] El triunfo de mi imaginación" (261). Atentando contra lo preestablecido, desbaratando el guión, Perlimplín relega al absurdo lo que ese orden impone, incuestionablemente como realidad, como verdad inamovible. De ahí su inaudito comentario "Ahora cierro los ojos y... veo lo que quiero... por ejemplo... a mi madre cuando la visitaron las hadas de los contornos... ¡ O Oh!... ¿ ¿ú sabes cómo son las hadas?... pequeñitas... jes admirable! ipueden bailar sobre mi dedo meñique!" (258). El descrédito del orden establecido, consecuencia de esa inversión de valores, pretende inducir al público a una inquietante reflexión sobre la credibilidad de lo preestablecido. Esta estrategia obedece al propósito satírico de obligar al público a mirar la realidad objetivamente, tal como es, con la esperanza de convertirlo en un revulsivo ${ }^{38}$.

Marcolfa, condicionada por esa perspectiva lineal del público, la misma que había impedido a Perlimplín ver más allá de lo superficial o aparente, lamenta el trastorno de su amo ("antes todo estaba liso", 258) e incapaz de alcanzar a ver lo que éste ("Antes no podía pensar en las cosas extraordinarias que tiene el mundo... Me quedaba en las puertas...", 258; "He aprendido muchas cosas y, sobre todo, puedo imaginarlas...", 254), reprende su comportamiento que considera indecente: "Pero ¿cómo es posible? ¡Que usted mismo fomente en su mujer el peor de los

tema de los amores del viejo y la niña corroborando la originalidad del desenlace de Amor de don Perlimplín con Belisa en su jardín. L. Fernández Cifuentes (1992), pp. 89-100.

37 "Inversión de valores" o "transvaloración" son términos acuñados por Nietzsche en su propuesta de cambiar los falsos valores que determinan la moral tradicional. Fernández Cifuentes también emplea la expresión "inversión de valores" a propósito de la transgresión de los valores morales tradicionales que supone La zapatera prodigiosa., L. Fernández Cifuentes (1986), p. 103.

${ }^{38}$ Me remito a las siguientes declaraciones de Federico García Lorca: "Una de las finalidades que persigo con mi teatro es precisamente aspaventar y aterrar un poco. Estoy seguro y contento de escandalizar. Quiero provocar revulsivos, a ver si se vomita de una vez todo lo malo del teatro actual...". Véase F. García Lorca (1997i), p. 612. 
pecados!" (259). Tras la escandalosa respuesta de Perlimplín “¡Porque don Perlimplín no tiene honor y quiere divertirse!", que reitera la canción burlesca que entona el propio Perlimplín: “¡Don Perlimplín no tiene honor!/ ¡No tiene honor!”, Marcolfa se despide de su servicio indignada, escandalizada por semejante falta de honor: "Sepa mi señor que desde este momento me considero despedida de su servicio. Las criadas tenemos también vergüenza" (259). Sin embargo, la deshonra que avergüenza a Marcolfa resulta irrelevante en contraste con la inminente muerte de Perlimplín, cuyo suicidio reniega del concepto calderoniano del honor avalado por la moral tradicional ${ }^{39}$. Ese código de comportamiento, "moral ridícula de las gentes" (257), es desacreditado, pues carece de relevancia al confrontarlo con el carácter definitivo de la muerte.

El descrédito de lo preestablecido culmina en la referencia burlesca de la creación implícita en la intervención de Perlimplín: “¡Ah, don Perlimplín! Viejo verde, monigote sin fuerzas, tú no podías gozar el cuerpo de Belisa... El cuerpo de Belisa era para músculos jóvenes y labios de ascuas..."(263). Además de la obvia e intencionada burla de sí mismo, las palabras empleadas por Perlimplín trascienden en una significación metafísica, que corroboraban las declaraciones de Federico García Lorca el día previo al estreno: "Esta 'aleluya erótica' es una obra tremenda que a mí me divierte mucho. Teatro de monigotes humanos, que empieza en burla y acaba en trágico" 40 . El indicativo "monigotes humanos" es una imagen caricaturesca de la creación, en la que hombre, hecho a imagen y semejanza de Dios, no es más que un monigote, un pelele. Lorca emplea de nuevo la técnica satírica de la reducción, pues recurre a la muñequización para degradar y desvalorizar al hombre mediante el rebajamiento de su estatura y dignidad ${ }^{41}$. Simultáneamente la figura de la divinidad sufre también una reducción ya que es degradada al rebajar su elevada condición a términos humanos, tal como se advierte en las connotaciones cristológicas atribuidas al personaje de Perlimplín, capaz de redimir con su sangre a Belisa y "recrearla”42. “'Belisa ya tiene un alma!” (263). M.E. Seco de Lucena llama a esta práctica "humanización y liliputización de la divinidad"43. Uno de los poemas de Lorca escogidos por Seco de Lucena para

39 Así lo advertía Federico García Lorca un día antes al estreno: "El héroe, o antihéroe, a quien hacen cornudo, es español y calderoniano; pero no quiere reaccionar calderonianamente, de ahí su lucha, la tragedia grotesca de su caso". F. García Lorca, (1997d), p. 406.

${ }^{40}$ Ibidem.

${ }^{41}$ Matthew Hodgart afirma: "La técnica básica del satírico es la reducción: la degradación o desvalorización de la víctima mediante el rebajamiento de su estatura o dignidad. M. Hodgart (1969), p. 115.

${ }^{42}$ Término empleado por Francisco García Lorca. Véase F. García Lorca (1981), p. 319.

${ }^{43}$ M.E. Seco de Lucena Vázquez de Gardner (1990), pp. 121-128. 
argumentar su teoría es "Saeta"44, cuyo verso "¡Miradlo por dónde viene!" reverbera en Amor de don Perlimplín cuando éste anuncia a Belisa la aparición del joven en el que se desdobla con casi idénticas palabras: "Míralo por dónde viene..." (262). La elección de Seco de Lucena, coincidiendo con ese verso de "Saeta" que Lorca pone en boca de Perlimplín, corrobora la intención reductiva de esta obra en la que vengo insistiendo.

La reducción de la divinidad a parámetros humanos, tanto físicos como de comportamiento, es frecuente en la obra de Lorca. Véanse las obras de juventud Jehová $^{45}$ y Dios, el Mal y el Hombre ${ }^{46}$ en las que las figuras celestiales, Dios y los ángeles, han degenerado hasta el peor de los comportamientos humanos. Lorca los retrata como seres pervertidos, sin ética ni moral, cuya actitud hace acopio de los siete pecados capitales, especialmente en Jehová. Obedeciendo a propósitos satíricos y sirviéndose de procedimientos reductivos propios de la farsa ${ }^{47}$, Lorca hace que lo elevado se precipite hasta el extremo radicalmente opuesto. Esta desacralización de la divinidad, propia de la sátira religiosa ${ }^{48}$, que Lorca lleva a cabo, da al traste con las argumentaciones de la Iglesia que justifican y condicionan la existencia y que, además, legitiman el poder de esta institución.

La aleluya, debido a las limitaciones propias del género, se prestaba a exageraciones burlescas, a la ridiculización, a la caricatura..., en definitiva: a la utilización de técnicas satíricas. El objeto de ataque contra el que arremeten dichas técnicas no sólo es la actitud de los personajes sino también el modelo de vida a imitar: las vidas de santos $^{49}$, lo cual cuestiona, implícitamente y de manera burlesca, los fundamentos de la moral impuesta. La costumbre, la tradición, la rigidez de lo normativo nos limita o encasilla, como lo están los monigotes en las viñetas de las aleluyas, haciéndonos parecer igual de ridículos y patéticos. Por tanto, emplear el género de la aleluya desvela un propósito reductivo. Además de la desvalorización de las instituciones sociales y de la moral tradicional, la reducción que Lorca lleva a cabo en esta hagiografía burlesca alcanza una dimensión existencial, porque la vida, por mucho que el dogma se empecine en lo contrario, no es tan simple ni superficial

\footnotetext{
${ }^{44}$ F. García Lorca, Saeta, en F. García Lorca (1997j), p. 319.

${ }^{45}$ F. García Lorca, Jehová, en F. García Lorca (1997k), pp. 1004-1010.

${ }^{46}$ F. García Lorca, Dios, el Mal y el Hombre, (19971), pp. 890-891.

${ }^{47}$ Urzáiz Tortajada también advierte en las obras de juventud a las que nos referimos "un tratamiento satírico o paródico, aunque en muchos casos García Lorca recurre a procedimientos teatrales farsescos”. H. Urzáiz Tortajada (1996), p. 389.

${ }_{48}^{48}$ M. Hodgart (1969), p. 39.

49 Fernández Cifuentes advierte: “la 'aleluya' pertenecía a un género extraordinariamente ritualizado: las secuencias de monigotes se atenían a una configuración prevista, estrechamente emparentada con la de los relatos de vidas de santos en los retablos populares, y reproducida con la misma rigidez”. L. Fernández Cifuentes (1986), p. 119.
} 
como la de los personajes de una aleluya. Es absurda la rigidez de la norma que trata de limitar la vida a una secuencia ritual.

Tal como se ha expuesto, la sátira desempeña un papel fundamental en Amor de don Perlimplín con Belisa en su jardín. En su "Aleluya erótica en cuatro cuadros", Lorca recurrió a procedimientos satíricos mediante los que rechazó la imposición de un saber legado por la tradición y los convencionalismos, desacreditó cualquier tipo de autoridad: la familiar, la social, la institucional..., y reivindicó la libertad al tiempo que proponía un teatro nuevo. En contraposición al realismo mimético que había prostituido el teatro ${ }^{50}$ y cuyo único propósito era el de complacer al espectador eludiendo cualquier aspecto crítico, Lorca hizo hincapié en los aspectos más escabrosos para reivindicar la realidad que resulta ser más auténtica.

\section{Obras citadas}

CORTÉS TOVAR, Rosario: Teoría de la sátira. Análisis de Apocolocyntosis de Séneca, Cáceres, Universidad de Extremadura, 1986.

FERNÁNDEZ CIFUENTES, Luis: García Lorca en el teatro: la norma y la diferencia, Zaragoza, Universidad de Zaragoza, 1986.

: "El viejo y la niña: tradición y modernidad en el teatro de Lorca", en El teatro en España, entre la tradición y la vanguardia, Madrid, C.S.I.C/ Fundación Federico García Lorca/ Tabacalera, 1992, pp. 89-102.

FRYE, Northrop: Anatomy of criticism, Princeton, Princeton University Press, 1973.

-———: Anatomía de la crítica, Venezuela, Monte Ávila editores, 1977.

GARCÍA LORCA, Federico: Obras completas, edición de M. García-Posada, Barcelona, Galaxia Gutenberg y Círculo de Lectores, 1997.

"Antes del estreno. Hablando con Federico García Lorca", La Libertad, 24 de diciembre de 1930, en F. García Lorca, Obras Completas, Vol. III, edición de M. García-Posada, Barcelona, Galaxia Gutenberg y Círculo de Lectores, 1997a, p. 374-376.

: Amor de don Perlimplín con Belisa en su jardín, en F. García Lorca, Obras Completas, Vol. II, edición de M. García-Posada, Barcelona, Galaxia Gutenberg y Círculo de Lectores, 1997b, pp. 240-264.

: El patriotismo, en F. García Lorca, Obras Completas, Vol. IV, edición de M. García-Posada, Barcelona, Galaxia Gutenberg y Círculo de Lectores, 1997c, pp. 731-736.

${ }^{50}$ Me remito a las palabras de Federico García Lorca durante la entrevista concedida a Miguel Pérez Ferrero el 14 de abril de 1934: "En España, la burguesía y la clase media, que han prostituido nuestro teatro, sabrán rectificar”. F. García Lorca, (199711), p. 532. 
: "Un estreno de García Lorca en el Español en gran función de gala", Heraldo de Madrid, 4 de abril de 1933, en F. García Lorca, Obras Completas, Vol. III, edición de M. García-Posada, Barcelona, Galaxia Gutenberg y Círculo de Lectores, 1997d, p. 406.

- - - -: "Charla sobre teatro" en F. García Lorca, Obras Completas, Vol. III, edición de M. García-Posada, Barcelona, Galaxia Gutenberg y Círculo de Lectores, 1997e, pp. 254-257.

: Dragón, en F. García Lorca, Obras Completas, Vol. II, edición de M. García-Posada, Barcelona, Galaxia Gutenberg y Círculo de Lectores, 1997f, pp. $762-764$.

- ———: La zapatera prodigiosa, en F. García Lorca, Obras Completas, Vol. II, edición de M. García-Posada, Barcelona, Galaxia Gutenberg y Círculo de Lectores, 1997g, pp. 196-237.

- - - Comedia sin título, en F. García Lorca, Obras Completas, Vol. II, edición de M. García-Posada, Barcelona, Galaxia Gutenberg y Círculo de Lectores, 1997h, pp. 769-786.

- - - "Conversación con F. G. L.", entrevista concedida a Ricardo G. Luengo, 15 de noviembre de 1935, en F. García Lorca, Obras Completas, Vol. III, edición de M. García-Posada, Barcelona, Galaxia Gutenberg y Círculo de Lectores, 1997i , pp. 611-616.

___— : Saeta, en F. García Lorca, Obras Completas, Vol. I, edición de M. García-Posada, Barcelona, Galaxia Gutenberg y Círculo de Lectores, 1997j, p. 319.

: Jehová, en F. García Lorca, Obras Completas, Vol. IV, edición de M. García-Posada, Barcelona, Galaxia Gutenberg y Círculo de Lectores, 1997k, pp. 1004-1010.

- - Dios, el Mal y el Hombre, en F. García Lorca, Obras Completas, Vol. IV, edición de M. García-Posada, Barcelona, Galaxia Gutenberg y Círculo de Lectores, 19971, pp. 890-891.

- ———: "Los españoles fuera de España. La renovación del teatro español", entrevista concedida a Miguel Pérez Ferrero, 14 de abril de 1934, en F. García Lorca, Obras Completas, Vol. III, edición de M. García-Posada, Barcelona, Galaxia Gutenberg y Círculo de Lectores, 19971l, p. 532.

GARCÍA LORCA, Francisco: Federico y su mundo, edición y prólogo de Mario Hernández, Madrid, Alianza, 1981.

GIBSON, Ian: Vida, pasión y muerte de Federico García Lorca, Barcelona, Plaza \& Janés, 1998.

GRANT, Helen: "Una aleluya erótica de Federico García Lorca y las aleluyas populares del siglo XIX", en Actas del Primer Congreso Internacional de Hispanistas: celebrado en Oxford del 6 al 11 de septiembre de 1962, Oxford, Dolphin Book, 1964, pp. 307-314. 
GUILLÉN, Claudio: Entre lo uno y lo diverso. Introducción a la literatura comparada, Barcelona, Crítica, 1985.

HIGGINBOTHAM, Virginia: The comic spirit of Federico García Lorca, Austin, University of Texas Press, 1976.

HIGHET, Gilbert: The anathomy of satire, Princeton, New Jersey, Princeton University Press, 1962.

HODGART, Matthew: La sátira, Madrid, Ediciones Guadarrama, 1969.

HUERTA CALVO, Javier: "La recuperación del entremés y los géneros teatrales menores en el primer tercio del siglo XX", en, El teatro en España, entre la tradición y la vanguardia, Madrid, C.S.I.C/ Fundación Federico García Lorca/ Tabacalera, 1992, pp. 285-294.

IGLESIAS SANTOS, Montserrat: "La farsa en el teatro de vanguardia europeo: Valle- Inclán y Ghelderode", en Sin fronteras: ensayos de literatura comparada en homenaje a Claudio Guillén, Santiago de Compostela, Universidad de Santiago de Compostela, 1999, pp. 163-174.

PERAL VEGA, Emilio: "Burla clásica, burla moderna: el personaje de Perlimplín", en Tiempo de burlas. En torno a la literatura burlesca del Siglo de Oro, Madrid, Editorial Verbum, 2001, pp. 223-244.

QUEVEDO, Francisco de: El mundo por de dentro, en Sueños y discursos, edición de O. Crosby, Madrid, Castalia, 1993.

SECO DE LUCENA VÁZQUEZ DE GARDNER, María Encarnación: La estética de lo pequeño y la reducción espacial en la obra de García Lorca, Granada, Universidad de Granada, 1990.

UCELAY, Margarita: "Introducción” a F. García Lorca, Amor de don Perlimplín con Belisa en su jardín, Madrid, Cátedra, 2005.

URZÁIZ TORTAJADA, Héctor: "Farsa, sátira y parodia en el teatro juvenil de García Lorca”, Cuadernos para la investigación de la literatura hispánica, 21, (1996), pp. 385-401.

VÉLEZ DE GUEVARA, Luis: El diablo cojuelo, edición de Ramón Valdés, Barcelona, Crítica, 1999.

VAÍlLO TORRES, Carlos: La poesía satírica de Francisco de Quevedo, Bellaterra, Departament de Filologia Espanyola i Catalana, Universitat Autònoma de Barcelona. Facultat de Filosofia i Lletres, 1977, Vol. 1, Tesis doctoral inédita.

WRIGHT, Sarah: The trickster-function in the theatre of García Lorca, Londres, Tamesis, 2000. 